\title{
Left ventricular performance in patients with left ventricular hypertrophy caused by systemic arterial hypertension ${ }^{1}$
}

\author{
JOEL S. KARLINER, DAVID WILLIAMS, JEFFREY GORWIT, \\ MICHAEL H. CRAWFORD, AND ROBERT A. O'ROURKE
}

From the Cardiovascular Division, Department of Medicine, University of California at San Diego, California, U.S.A.

To assess the adaptation of the left ventricle to a chronic pressure overload we used echocardiography to study 18 patients with left ventricular hypertrophy caused by systemic arterial hypertension. Increased values for either posterior wall or interventricular septal thickness or both confirmed the presence of left ventricular hypertrophy in all patients and an increase in the average wall thickness to radius ratio was consistent with the development of concentric hypertrophy. No patient had clinical evidence of ischaemic heart disease. Ejection phase indices of left ventricular performance (mean Vcf, fractional per cent of shortening, normalised posterior wall velocity, and ejection fraction) were within the normal range in the basal state in 16 of the 18 patients. The hypothesis is advanced that patients with concentric left ventricular hypertrophy resulting from systemic arterial hypertension usually have normal left ventricular performance in the basal state because values for wall stress remain within the normal range. We conclude that the hypertrophic response to a chronic increase in systemic arterial pressure does not per se result in depression of the basal inotropic state of the left ventricle.

There is considerable controversy concerning myocardial performance in hypertrophied states. Data derived from in vitro and in vivo experiments as well as available information in human studies suggest that ventricular function is depressed as a result of hypertrophy (Spann et al., 1967, 1969; Bing et al., 1971; Frohlich et al., 1971; Spann et al., 1972; Gunning et al., 1973; Alpert et al., 1974; Mehmel et al., 1975). However, more recent animal experiments suggest that performance is normal in the absence of overt congestive heart failure (Gamble et al., 1973; Malik et al., 1974; Pfeffer et al., 1976; Sasayama et al., 1976). Systemic arterial hypertension is a common cause of left ventricular hypertrophy and in this study we sought to define the functional state of the left ventricle in 18 patients with left ventricular hypertrophy caused by a raised systemic blood pressure. A noninvasive technique, echocardiography, was used to assess left ventricular performance.

'Supported in part by a National Heart, Lung and Blood Institute Graduate Training Grant.

Received for publication 22 December 1976

\section{Methods}

The study group consisted of 9 men and 9 women ranging in age from 21 to 72 years (mean $=48$ ). Of these patients, 8 were black, 4 Mexican-American, and 6 Caucasian. At the time of study, most patients were receiving treatment for high blood pressure. However, no patient was receiving a digitalis glycoside, reserpine, or guanethidine. Other treatment is detailed in the Table. Systolic arterial pressure (cuff method) at the time of study averaged $170 \mathrm{mmHg}$ systolic with a range of 130 to 200 $\mathrm{mmHg}$. Diastolic arterial pressure averaged 104 mmHg with a range of 75 to $140 \mathrm{mmHg}$. Heart rate averaged 66 beats/min (range 50 to 79). Each patient had left ventricular hypertrophy by the highly specific electrocardiographic criteria described by Romhilt and Estes (1968), by the vectorcardiographic criteria as described by Chou et al. (1974), or both. Though two-thirds of our patients had an increased cardiothoracic ratio $(>0.5)$, standard chest radiography was not used to assess left ventricular enlargement because of the substantial number of false positive and false negative results obtained 
Table Clinical and ultrasound data

\begin{tabular}{|c|c|c|c|c|c|c|c|c|c|c|c|c|c|c|}
\hline \multirow{2}{*}{$\begin{array}{l}\text { Case } \\
\text { No. }\end{array}$} & \multirow[t]{2}{*}{ Sex } & \multirow[t]{2}{*}{ Age (y) } & \multirow{2}{*}{$\begin{array}{l}H R \\
(b p m)\end{array}$} & \multicolumn{2}{|c|}{$S A P(\operatorname{mm} H g)$} & \multirow{2}{*}{$\begin{array}{l}E D D \\
(\mathbf{m m})\end{array}$} & \multirow{2}{*}{$\% \Delta D$} & \multirow{2}{*}{$\begin{array}{l}\text { Mean Vcf } \\
(\operatorname{diam} / s)\end{array}$} & \multirow{2}{*}{$\begin{array}{l}V p w \\
\left(s^{-1}\right)\end{array}$} & \multirow[t]{2}{*}{$E F(\%)$} & \multicolumn{2}{|c|}{ Septal thickness } & \multicolumn{2}{|c|}{$P W$ thickness } \\
\hline & & & & $S$ & $D$ & & & & & & $\begin{array}{l}\text { Pre-P } \\
\text { (mm) }\end{array}$ & $\begin{array}{l}E D \\
(\mathrm{~mm})\end{array}$ & $\begin{array}{c}\text { Pre-P } \\
(\mathrm{mm})\end{array}$ & $\begin{array}{l}E D \\
(\mathrm{~mm})\end{array}$ \\
\hline $\begin{array}{l}1 \\
2 \\
3\end{array}$ & $\begin{array}{l}\mathbf{F} \\
\mathbf{F} \\
\mathbf{F}\end{array}$ & $\begin{array}{l}46 \\
21 \\
55\end{array}$ & $\begin{array}{l}72 \\
79 \\
71\end{array}$ & $\begin{array}{l}150 \\
200 \\
200\end{array}$ & $\begin{array}{r}100 \\
140 \\
80\end{array}$ & $\begin{array}{l}42 \cdot 8 \\
34 \cdot 7 \\
60 \cdot 0\end{array}$ & $\begin{array}{l}35 \\
39 \\
45\end{array}$ & $\begin{array}{l}1.23 \\
1.39 \\
1.33\end{array}$ & $\begin{array}{l}0.78 \\
0.82 \\
0.52\end{array}$ & $\begin{array}{l}74 \\
77 \\
83\end{array}$ & $\begin{array}{r}12 \cdot 6 \\
7 \cdot 3 \\
15 \cdot 2\end{array}$ & $\begin{array}{r}11.0 \\
6.3 \\
13.5\end{array}$ & $\begin{array}{l}16.8 \\
11.5 \\
14.6\end{array}$ & $\begin{array}{l}14.6 \\
11.3 \\
11.8\end{array}$ \\
\hline $\begin{array}{r}4 \\
5 \\
6 \\
7 \\
8 \\
9 \\
10 \\
11 \\
12 \\
13 \\
14 \\
15 \\
16 \\
17 \\
18\end{array}$ & $\begin{array}{l}\text { F } \\
M \\
M \\
\text { F } \\
\text { F } \\
\text { F } \\
\text { M } \\
\text { F } \\
\text { M } \\
\text { F } \\
\text { M } \\
\text { M } \\
M \\
M \\
M\end{array}$ & $\begin{array}{l}54 \\
39 \\
36 \\
34 \\
42 \\
54 \\
53 \\
67 \\
50 \\
60 \\
48 \\
43 \\
50 \\
72 \\
34\end{array}$ & $\begin{array}{l}72 \\
70 \\
70 \\
71 \\
75 \\
63 \\
71 \\
50 \\
58 \\
68 \\
56 \\
63 \\
58 \\
63 \\
64\end{array}$ & $\begin{array}{l}148 \\
190 \\
200 \\
170 \\
165 \\
190 \\
200 \\
160 \\
168 \\
160 \\
132 \\
160 \\
130 \\
135 \\
200\end{array}$ & $\begin{array}{r}80 \\
135 \\
130 \\
100 \\
100 \\
110 \\
110 \\
75 \\
105 \\
92 \\
88 \\
110 \\
105 \\
80 \\
130\end{array}$ & $\begin{array}{l}45.0 \\
40.3 \\
46.4 \\
43.6 \\
35.7 \\
51.0 \\
44.9 \\
40.6 \\
41.1 \\
36.8 \\
52.4 \\
65.5 \\
48.4 \\
51.2 \\
51.6\end{array}$ & $\begin{array}{l}38 \\
40 \\
38 \\
47 \\
36 \\
50 \\
45 \\
35 \\
37 \\
41 \\
36 \\
28 \\
24 \\
36 \\
20\end{array}$ & $\begin{array}{l}1.27 \\
1.66 \\
1.15 \\
1.59 \\
1.38 \\
1.79 \\
1.54 \\
1.09 \\
1.32 \\
1.28 \\
1.25 \\
1.00 \\
0.86 \\
1.04 \\
0.71\end{array}$ & $\begin{array}{l}0.91 \\
1.03 \\
0.84 \\
1.13 \\
0.99 \\
1.07 \\
1.04 \\
0.81 \\
0.95 \\
0.63 \\
0.68 \\
0.74 \\
0.80 \\
0.62 \\
0.61\end{array}$ & $\begin{array}{l}76 \\
81 \\
75 \\
85 \\
74 \\
87 \\
91 \\
72 \\
71 \\
80 \\
74 \\
63 \\
61 \\
73 \\
47\end{array}$ & $\begin{array}{l}12.0 \\
15.5 \\
12.6 \\
- \\
- \\
10.0 \\
13.0 \\
12.5 \\
14.5 \\
7.1 \\
10.6 \\
17.0 \\
12.6 \\
12.6 \\
19.0\end{array}$ & $\begin{array}{r}10.2 \\
13.5 \\
12.6 \\
- \\
- \\
6.6 \\
11.0 \\
11.9 \\
14.6 \\
9.7 \\
10.6 \\
17.0 \\
12.0 \\
13.2 \\
18.2\end{array}$ & $\begin{array}{l}11 \cdot 4 \\
18 \cdot 2 \\
15 \cdot 1 \\
13 \cdot 2 \\
14 \cdot 6 \\
13 \cdot 4 \\
17 \cdot 2 \\
16 \cdot 2 \\
13 \cdot 2 \\
11 \cdot 4 \\
13 \cdot 0 \\
17 \cdot 0 \\
10 \cdot 5 \\
15.5 \\
19.9\end{array}$ & $\begin{array}{r}11.4 \\
13.3 \\
13.0 \\
11.5 \\
12.4 \\
11.9 \\
14.5 \\
11.8 \\
14.3 \\
11.0 \\
10.6 \\
15.4 \\
8.9 \\
13.6 \\
17.6\end{array}$ \\
\hline $\begin{array}{l}\text { Mean } \\
\text { SE }\end{array}$ & - & 48 & $\begin{array}{l}66 \\
1 \cdot 7\end{array}$ & $\begin{array}{r}170 \\
5.9\end{array}$ & $\begin{array}{r}104 \\
4 \cdot 7\end{array}$ & $\begin{array}{r}46.2 \\
1.9\end{array}$ & $\begin{array}{l}37 \\
1 \cdot 8\end{array}$ & $\begin{array}{l}1.27 \\
0.06\end{array}$ & $\begin{array}{l}0.83 \\
0.04\end{array}$ & $\begin{array}{l}75 \\
2 \cdot 4\end{array}$ & $\begin{array}{r}12.7 \\
0.8\end{array}$ & $\begin{array}{r}12.0 \\
0.8\end{array}$ & $\begin{array}{r}14.6 \\
0.6\end{array}$ & $\begin{array}{r}12.7 \\
0.5\end{array}$ \\
\hline
\end{tabular}

SE, standard error; HR, heart rate; SAP, systemic arterial pressure; $S$, systolic; D, diastolic; EDD, end-diastolic diameter; \% $\Delta \mathrm{D}$, per cent change internal diameter; mean Vcf and Vpw : see text; EF, ejection fraction; S/PWT, ratio of septal to posterior wall thickness; hed/r, ratio of posterior $w$ thickness to internal radius (EDD/2).

with this method (Glover et al., 1973). It has also been shown that $x$-ray evidence of cardiomegaly was present in only 5 of 112 patients with systemic arterial hypertension who had evidence of left ventricular hypertrophy by ultrasound methods (Drayer et al., 1976).

No patient had a history of previous myocardial infarction or angina pectoris, and none had an intraventricular conduction defect or evidence of previous transmural myocardial infarction on the electrocardiogram. Two patients (cases 16 and 18 in the Table) had recently recovered from an episode of congestive heart failure associated with accelerated hypertension. No other patients had a history of congestive heart failure and none had signs of left ventricular decompensation (pulmonary râles, third heart sound) at the time of study. To obtain this group of 18 patients who met criteria for inclusion into the study, 200 patients attending a hypertension clinic were carefully screened.

Echocardiograms were obtained in the basal state using a Picker Ultrasonoscope employing a $2 \cdot 25$ $\mathrm{MHz}$ transducer focused at $7.5 \mathrm{~cm}$ with a repetition rate of 1000 impulses/s. The output signal was recorded on a Honeywell Visicorder Oscillograph (model 1856) at a paper speed of either 50 or 100 $\mathrm{mm} / \mathrm{s}$. Echocardiograms were obtained with the subjects in the partial left lateral decubitus position. The ultrasound beam was directed so that simultaneous recordings of the endocardial surfaces of

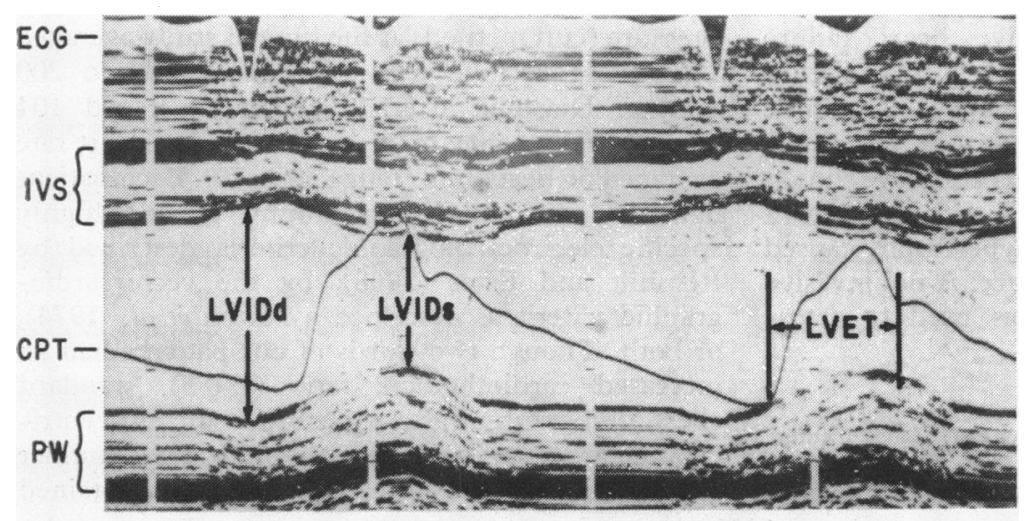

Fig. The left ventricular dimensions used for calculation of ejection phase indices are illustrated. ECG, electrocardiogram; IVS, interventricular septum; $P W$, posterior wall; $C P T$, carotid pulse tracing; LVET, left ventricular ejection time; $L V I D d$, left ventricular internal dimension at end-diastole; $L V I D$ s, left ventricular internal dimension at end-systole. 


\begin{tabular}{|c|c|c|c|c|c|}
\hline \multirow{2}{*}{$\begin{array}{l}S / P W T \\
(\text { Pre-P) }\end{array}$} & \multirow[t]{2}{*}{$h_{\mathrm{ed}} / r$} & \multirow{2}{*}{$\begin{array}{l}\text { Wall stress } \\
\left(\mathrm{g} / \mathrm{cm}^{2}\right)\end{array}$} & \multicolumn{3}{|l|}{ Drugs } \\
\hline & & & $\alpha$-methyldopa & Thiazide & Other \\
\hline 0.75 & 0.68 & 128 & - & - & - \\
\hline 0.63 & 0.65 & 188 & + & + & - \\
\hline 1.03 & $0 \cdot 39$ & 178 & - & - & $\begin{array}{l}\text { Clonidine, } \\
\text { frusemide }\end{array}$ \\
\hline 1.05 & 0.51 & 138 & + & - & - \\
\hline 0.85 & 0.66 & 179 & + & - & - \\
\hline 0.83 & 0.56 & 203 & - & + & - \\
\hline - & 0.53 & 177 & - & - & - \\
\hline - & 0.69 & 126 & + & + & - \\
\hline 0.75 & 0.47 & 206 & + & + & - \\
\hline $0 \cdot 76$ & 0.65 & 149 & - & - & - \\
\hline $0 \cdot 77$ & 0.59 & 113 & + & + & - \\
\hline $1 \cdot 1$ & 0.69 & 132 & + & + & - \\
\hline 0.62 & 0.60 & 142 & + & + & - \\
\hline $1 \cdot 0$ & 0.82 & 198 & - & + & Propranolol \\
\hline $1 \cdot 0$ & 0.47 & 205 & + & - & Hydrallazine \\
\hline $1 \cdot 2$ & $0 \cdot 37$ & 250 & + & + & \\
\hline 0.81 & 0.53 & 132 & - & + & Triamterene \\
\hline 0.95 & 0.68 & 167 & + & + & - \\
\hline $\begin{array}{l}0.95 \\
0.05\end{array}$ & $\begin{array}{l}0.56 \\
0.03\end{array}$ & $\begin{array}{l}167 \\
8 \cdot 7\end{array}$ & & & \\
\hline
\end{tabular}

the interventricular septum and the posterior left ventricular wall were obtained immediately below the plane of the free edges of the mitral valve (Hirshleifer et al., 1975),(Figure), using the 'standard interspace' method described by Popp et al. (1975). No patient had paradoxical septal motion (Hagan et al., 1974). The left ventricular internal dimension at end-diastole was measured at a point on the time motion scan coincident with the $R$ wave of the electrocardiogram. The left ventricular internal dimension at end-systole was defined as the smallest distance separating the left ventricular endocardial surfaces even if the points of maximum excursion were not exactly opposed. The left ventricular ejection time was measured using a simultaneously obtained carotid arterial pulse tracing. Diastolic posterior left ventricular wall thickness and interventricular septal thickness were measured at the onset of the $P$ wave and at the peak of the $R$ wave.

For each patient calculations of ejection phase indices of left ventricular performance were derived using the average of the measurements from five beats in each instance. The mean normalised rate of internal diameter shortening (mean Vcf) was calculated by subtracting the end-systolic diameter from the end-diastolic diameter and dividing the result by the ejection time and the end-diastolic diameter (Karliner et al., 1971b, 1974). The per cent change of internal diameter shortening was also calculated. Mean normalised posterior wall velocity
(Vpw) was derived by measuring posterior wall excursion in $\mathrm{cm} / \mathrm{s}$ and dividing by the ejection time and the end-diastolic diameter (Quinones et al., 1974; Hirshleifer et al., 1975). Ejection fraction was calculated as the ratio of stroke volume to enddiastolic volume using the method of Pombo et al. (1971).

To substantiate further the presence of concentric left ventricular hypertrophy, the ratio of wall thickness to end-diastolic radius $\left(h_{\mathrm{ed}} / \mathbf{r}\right)$ was calculated in each patient. It has previously been shown that an increase in this ratio occurs in the presence of concentric left ventricular hypertrophy (Grossman et al., 1975).

Since accurate measurements of end-diastolic dimensions, wall thickness, and systemic diastolic pressure were available, these values were used for the estimation of left ventricular wall stress employing an ellipsoid model (Karliner et al., 1971b). It has been reported by Ratshin et al. (1974) that this echocardiographic method of estimating wall stress correlates well with angiographic techniques.

\section{Results}

(1) MEASUREMENTS OF WALL THICKNESS Left ventricular posterior wall thickness measured at the onset of the $P$ wave of the electrocardiogram averaged $14.6 \pm 0.6(\mathrm{SE}) \mathrm{mm}$. In 17 of 18 patients this value exceeded $11 \mathrm{~mm}$, which is the upper limit of normal in our laboratory and is in agreement with previously published values (Feigenbaum, 1972; Henry et al., 1973). Interventricular septal thickness measured at the onset of the $P$ wave averaged $12.7 \pm 0.8 \mathrm{~mm}$. This value exceeded the normal upper limit of $11 \mathrm{~mm}$ in 12 of 16 patients in whom it was measured. Similar results were obtained when wall thickness was measured at enddiastole (Table). Thus, all patients with left ventricular hypertrophy by electrocardiogram or vectorcardiogram also had either increased left ventricular posterior or interventricular septal wall thickness or both by ultrasound. The ratio of interventricular septal to left ventricular posterior wall thickness at the onset of the $P$ wave was normal in all patients in whom it was measured, and ranged from 0.62 to $1 \cdot 20$.

\section{(2) EJECTION PHASE INDICES OF}

LEFT VENTRICULAR PERFORMANCE

Mean Vcf in the basal state averaged $1.27 \pm 0.06$ diameters (diam) $\mathrm{s}^{-1}$ and ranged from 0.71 to 1.79 diam s ${ }^{-1}$. The mean Vcf of only 2 patients fell below the lower limits of normal which in our laboratory is 1.00 diam $\mathrm{s}^{-1}$. Mean Vpw averaged $0.83 \pm 0.04 \mathrm{~s}^{-1}$ with a range of 0.52 to $1.13 \mathrm{~s}^{-1}$. All 
patients had values which were within the normal range for our laboratory. Ejection fraction averaged $75 \pm 2.4$ per cent with a range of 47 to 91 per cent. Only 3 patients had reduced values $(<67 \%)$. The change in internal diameter averaged $37 \pm 1.8$ per cent, with a range of 20 to 50 per cent, and only 2 patients had reduced values for this measure $(<28 \%)$. The end-diastolic diameter was normal in all but 2 patients $(<56 \mathrm{~mm})$.

\section{(3) ULTRASOUND ASSESSMENT OF CONCENTRIC HYPERTROPHY}

The average ratio of wall thickness to end-diastolic radius $\left(h_{\mathrm{ed}} / \mathrm{r}\right)$ was $0.56 \pm 0.03$. This value is significantly greater than that observed in 29 normal subjects recently studied in our laboratory $(0.34 \pm$ $0.02, \mathrm{P}<0.00001$, unpaired $\mathrm{t}$ test).

\section{(4) WALL STRESS}

Wall stress in the 18 patients with left ventricular hypertrophy averaged $167 \pm 8.7 \mathrm{~g} / \mathrm{cm}^{2}$. This value did not differ significantly from that obtained in 29 normal subjects recently studied in our laboratory under basal conditions $\left(172 \pm 6 \cdot 6 \mathrm{~g} / \mathrm{cm}^{2}\right)$.

\section{Discussion}

The results of the present study indicate that in the majority of patients with left ventricular hypertrophy caused by systemic arterial hypertension, the mechanical performance of the hypertrophied heart in the basal state remains within the normal range. Only 3 of the 18 patients had depressed values for ejection phase indices of left ventricular performance and 2 of these (cases 16 and 18 ) had recently recovered from an episode of congestive heart failure resulting from accelerated hypertension.

\section{PREVIOUS STUDIES IN PATIENTS WITH}

LEFT VENTRICULAR HYPERTROPHY

Much of the evidence concerning the mechanical performance of the nonfailing, hypertrophied myocardium is conflicting, and little information is available from previous studies in human subjects. Toshima et al. (1975) reported a normal echocardiographic ejection fraction in 11 patients with concentric left ventricular hypertrophy caused by systemic arterial hypertension. By contrast, Frohlich and his colleagues (1971) described a reduction in resting cardiac output, stroke index, and left ventricular ejection rate in hypertensive patients with left ventricular hypertrophy. In a study using systolic time intervals to assess left ventricular performance, Dodek et al. (1975) concluded that a substantial proportion of patients with untreated hypertension had impaired left ventricular performance. In patients with aortic stenosis without heart failure, a depression in left ventricular 'contractility' as measured by isovolumic indices has been reported (Spann et al., 1969; Simon et al., 1970). However, the accuracy of such measurements of left ventricular performance has recently been questioned (Karliner et al., 1974). Since one of the adaptations to a chronic increase in afterload is an increase in muscle mass, i.e. an increase in the number of sarcomeres within cells (Bishop, 1971), we have evaluated left ventricular performance using ejection phase indices normalised per unit of circumference. Such measures should detect basal depression of inotropic state after the adaptation to a chronic increase in afterload has occurred (Sasayama et al., 1976).

\section{EXPERIMENTAL STUDIES OF}

\section{VENTRICULAR HYPERTROPHY}

Although it is generally accepted that experimentally induced chronic volume overload that does not result in overt congestive cardiac failure does not lead to a depression of left ventricular performance (Cooper et al., 1973; Ross, 1974), there is considerable controversy concerning ventricular performance in experimentally induced chronic pressure overload. In studies using isolated papillary muscle preparations, it was concluded that the induction of ventricular hypertrophy led to a depression of the contractile state of the myocardium (Spann et al., 1967; Bing et al., 1971; Spann et al., 1972; Gunning et al., 1973; Alpert et al., 1974). In a more recent study, however, Williams and Potter (1974) showed that, while myocardial depression did occur early (6 weeks) after pulmonary artery banding, the contractile state of papillary muscles removed from cats that survived 24 weeks was normal. These investigators concluded that a depressed contractile state was not a fundamental characteristic of pressure-induced hypertrophy. Recent experiments (Pfeffer and Frohlich, 1973; Malik et al., 1974; Sasayama et al., 1976) tend to support these conclusions, and are in agreement with our own observations in hypertensive patients with left ventricular hypertrophy. Thus, the majority of our patients were in the stable stage (Meerson stage II (Meerson, 1969)) of hypertension which has been shown in the conscious dog with aortic constriction (Sasayama et al., 1976) as well as in the spontaneously hypertensive rat (Pfeffer et al., 1976). Whether acutely induced alterations in heart rate and systemic arterial pressure would detect abnormalities of left ventricular performance not observed in the basal state is open to question. However, we did not feel justified in producing acute alterations in haemo- 
dynamics in patients whose systemic arterial pressure was already raised.

CONSIDERATIONS REGARDING WALL STRESS One explanation of why left ventricular performance was in the normal range in most of our patients with left ventricular hypertrophy is that a compensatory increase in wall thickness reduces wall stress and so permits the left ventricle to shorten against a relatively normal afterload. In 1960, Linzbach proposed that hypertrophy was a compensatory mechanism that increased until the force generated per cross-sectional unit of left ventricular wall returned to normal values. We used the available ultrasound measurements of end-diastolic dimentions, wall thickness, and systemic diastolic pressure to estimate left ventricular wall stress using an ellipsoid model (Karliner et al., 1971b). In support of the use of these measurements to estimate wall stress, it should be pointed out that minimal alterations in left ventricular dimensions occur during isovolumic systole (Karliner et al., 1971a), and that we were unable to detect any significant alterations in wall thickness during isovolumic contractions by echocardiography. As indicated earlier, this echocardiographic method of estimating wall stress correlates well with angiocardiographic techniques (Ratshin et al., 1974).

We are aware, however, that there are certain assumptions underlying such calculations of wall stress. The stresses calculated by the LaPlace formula or any of its variations represent mean values across the thickness of the wall. As Hood et al. (1968) have pointed out, the mean value underestimates maximal stress, which occurs toward the endocardial layers, and overestimates minimal stress, which occurs toward the epicardial layers. Moreover, it was not possible to estimate either enddiastolic or peak stress, since our study was a noninvasive one, and measurements of intracavitary left ventricular pressures were not available. Nevertheless, the observation that wall stress values obtained at approximately the time of aortic valve opening (systemic diastolic pressure) do not differ from values obtained in normal subjects provides one explanation of why left ventricular performance may remain normal in the face of a chronic increase in systemic arterial pressure. These observations are also in agreement with the hypothesis of Grossman et al. (1975) who proposed that hypertrophy develops to normalise systolic wall stress. In addition, the latter investigators noted that peak wall stress values in patients with concentric left ventricular hypertrophy caused by chronic pressure overload resulting from aortic stenosis also did not differ from values obtained in normal subjects.
ASSESSMENT OF CONCENTRIC HYPERTROPHY The average ratio of wall thickness to end-diastolic radius $\left(h_{\mathrm{ed}} / \mathbf{r}\right)$ was 0.56 , which is almost identical to the value recently reported in patients with chronic pressure overload caused by aortic valvular stenosis (Grossman et al., 1975). As indicated in the Results section, this value significantly exceeded average values in 29 normal subjects. Such an increase in $h_{e d} / r$ is further evidence in favour of the presence of concentric left ventricular hypertrophy in our patients, and is characteristic of the adaptation of the left ventricular chamber to a chronic pressure overload (Levine et al., 1963; Grant et al., 1965; Simon et al., 1970).

\section{CONSIDERATION OF DRUG THERAPY}

We recognise that at the time of study many of our patients were receiving drugs which could influence extracellular volume, peripheral resistance, and cardiac output, alone or in combination. Because of the clinical circumstances under which the study was conducted, however, it was not possible to withhold antihypertensive treatment. Nevertheless, inspection of the Table reveals that in the 3 patients who were receiving no treatment at the time of study, left ventricular performance was normal and values did not differ from the other treated patients with normal left ventricular function. Further, the one patient who was receiving propranolol, in whom some depression of cardiac function might have been expected, also had normal left ventricular performance. It should also be emphasised that despite anti-hypertensive treatment in the majority of patients, concentric hypertrophy was present in all.

\section{RELATION OF SYSTEMIC ARTERIAL HYPERTENSION TO CARDIAC \\ DECOMPENSATION}

Finally, it is well known that systemic arterial hypertension is a common cause of congestive cardiac failure. Our data are consistent with a recently advanced hypothesis that the heart with a sufficient "basal level of contractility can compensate for a chronic pressure overload by hypertrophy to maintain a normal mean Vcf, i.e. normal mechanical performance per unit of circumference. However, when all reserve mechanisms, including hypertrophy and the Frank-Starling mechanism, are maximally used, a further increase in afterload may produce a 'mismatch' between afterload and contractility (Ross, 1976), and thus lead to congestive cardiac failure.

\section{References \\ Alpert, N. R., Hamrell, B. B., and Halpern, W. (1974). Mechanical and biochemical correlates of cardiac hyper-}


trophy. Circulation Research, 34 and 35, Suppl. 2, 71-82.

Bing, O. H. L., Matsushita, S., Fanburg, B. L., and Levine, H. J. (1971). Mechanical properties of rat cardiac muscle during experimental hypertrophy. Circulation Research, 28, 234-245.

Bishop, S. P. (1971). Ultrastructural alterations in canine myocardial hypertrophy. In Cardiac Hypertrophy, pp. 107-124. Ed. by N. P. Alpert. Academic Press, New York.

Chou, T-C., Helm, R. A., and Kaplan, S. (1974). (Eds.) Clinical Vectorcardiography, 2nd ed., pp. 71-84. Grune and Stratton, New York.

Cooper, G., IV, Puga, F. J., Zujko, K. J., Harrison, C. E., and Coleman, H. N., III (1973). Normal myocardial function and energetics in volume-overload hypertrophy in the cat. Circulation Research, 32, 140-148.

Dodek, A., Burg, J. R., and Kloster, F. E. (1975). Systolic time intervals in chronic hypertension: alterations and response to treatment. Chest, 68, 51-55.

Drayer, J. I. M., Savage, D. D., Henry, W. L., Mathews, E. C., Laragh, J. H., and Epstein, S. H. (1976). Incidence of echocardiographic left ventricular hypertrophy and left atrial enlargement in essential hypertension (abstract). Circulation, 53 and 54, Suppl. II, 233.

Feigenbaum, H. (1972). Echocardiography, p. 216. Lea and Febiger, Philadelphia.

Frohlich, E. D., Tarazi, R. C., and Dustan, H. P. (1971). Clinical-physiological correlations in the development of hypertensive heart disease. Circulation, 44, 446-455.

Gamble, W. J., Phornphutkul, C., Kumar, A. E., Sanders, G. L., Manasek, F. J., and Monroe, R. G. (1973). Ventricular performance, coronary flow, and $\mathrm{MV}_{\mathrm{O}_{2}}$, in aortic coarctation hypertrophy. American fournal of Physiology, 224, 877-883.

Glover, L., Baxley, W. A., and Dodge, H. T. (1973). A quantitative evaluation of heart size measurements from chest roentgenograms. Circulation, 47, 1289-1296.

Grant, C., Greene, D. G., and Bunnell, I. L. (1965). Left ventricular enlargement and hypertrophy. A clinical and angiocardiographic study. American Fournal of Medicine, 39, 895-904.

Grossman, W., Jones, D., and McLaurin, L. P. (1975). Wall stress and patterns of hypertrophy in the human left ventricle. Fournal of Clinical Investigation, 56, 56-64.

Gunning, J. F., Cooper, G., IV, Harrison, C. E., and Coleman, H. N., III (1973). Myocardial oxygen consumption in experimental hypertrophy and congestive heart failure due to pressure overload. American fournal of Cardiology, 32, 427-436.

Hagan, A. D., Francis, G., Sahn, D., Karliner, J. S., Friedman, W., and O'Rourke, R. A. (1974). Ultrasound evaluation of systolic anterior septal motion in patients with and without ventricular volume overload. Circulation, 50, 248254.

Henry, W. L., Clark, C. E., and Epstein, S.' E. (1973). Asymmetric septal hypertrophy. Echocardiographic identification of the pathognomonic anatomic abnormality of IHSS. Circulation, 47, 225-233.

Hirshleifer, J., Crawford, M., O'Rourke, R. A., and Karliner, J. S. (1975). Influence of acute alterations in heart rate and systemic arterial pressure on echocardiographic measures of left ventricular performance in normal human subjects. Circulation, 52, 835-841.

Hood, W. P., Jr., Rackley, C. E., and Rolett, E. L. (1968). Wall stress in the normal and hypertrophied human left ventricle. American fournal of Cardiology, 22, 550-558.

Karliner, J. S., Bouchard, R. J., and Gault, J. H. (1971a). Dimensional changes of the human left ventricle prior to aortic valve opening. Circulation, 44, 312-322.

Karliner, J. S., Gault, J. H., Eckberg, D., Mullins, C. B., and
Ross, J., Jr. (1971b). Mean velocity of fibre shortening: a simplified measure of left ventricular myocardial contractility. Circulation, 44, 323-333.

Karliner, J. S., Peterson, K. L., and Ross, J., Jr. (1974). Myocardial mechanics. In Cardiac Catheterization and Angiography, pp. 293-303. Ed. by W. Grossman. Lea and Febiger, Philadelphia.

Levine, N. D., Rockoff, S. D., and Braunwald, E. (1963). An angiocardiographic analysis of the thickness of the left ventricular wall and cavity in aortic stenosis and other valvular lesions. Circulation, 28, 339-345.

Linzbach, A. J. (1960). Heart failure from the point of view of quantitative anatomy. American fournal of Cardiology, $5,370-382$.

Malik, A. B., Abe, T., O'Kane, H. O., and Geha, A. S. (1974). Cardiac performance in ventricular hypertrophy induced by pressure and volume overloading. Fournal of Applied Physiology, 37, 867-874.

Meerson, F. (1969). The myocardium in hyperfunction, hypertrophy and heart failure. Circulation Research, 2425, Suppl. II, 1-163.

Mehmel, H. C., Mazzoni, S., and Krayenbuehl, H. P. (1975) Contractility of the hypertrophied human left ventricle in chronic pressure and volume overload. American Heart fournal, 90, 236-240.

Pfeffer, M. A., and Frohlich, E. D. (1973). Hemodynamic and myocardial function in young and old normotensive and spontaneously hypertensive rats. Circulation Research, 32 and 33, Suppl. I, 28-38.

Pfeffer, M. A., Pfeffer, J. M., and Frohlich, E. D. (1976). Pumping ability of the hypertrophying left ventricle of the spontaneously hypertensive rat. Circulation Research, 38, 423-429.

Pombo, J. F., Troy, B. L., and Russell, R. O., Jr. (1971). Left ventricular volumes and ejection fraction by echocardiography. Circulation, 43, 480-490.

Popp, R. L., Filly, K., Brown, O. R., and Harrison, D. C. (1975). Effect of transducer placement on echocardiographic measurement of left ventricular dimensions. American fournal of Cardiology, 35, 537-540.

Quinones, M. A., Gaasch, W. H., and Alexander, J. K. (1974). Echocardiographic assessment of left ventricular function. With special reference to normalized velocities. Circulation, $50,42-51$.

Ratshin, R. A., Rackley, C. E., and Russell, R. O., Jr. (1974). Determination of left ventricular preload and afterload by quantitative echocardiography in man: calibration of the method. Circulation Research, 34, 711-718.

Romhilt, D. W., and Estes, E. H. (1968). A point-score system for the ECG diagnosis of left ventricular hypertrophy. American Heart fournal, 75, 752-758.

Ross, J., Jr. (1974). Adaptations of the left ventricle to chronic volume overload. Circulation Research, 34 and 35, Suppl. II, 64-70.

Ross, J., Jr. (1976). Afterload mismatch and preload reserve: a conceptual framework for the analysis of ventricular function. Progress in Cardiovascular Diseases, 18, 255-264.

Sasayama, S., Ross, J., Jr., Franklin, D., Bloor, C. M., Bishop, S., and Dilley, R. B. (1976). Adaptations of the left ventricle to chronic pressure overload. Circulation Research, 38, 172-178.

Simon, H., Krayenbuehl, H. P., Rutishauser, W., and Preter, B. O. (1970). The contractile state of the hypertrophied left ventricular myocardium in aortic stenosis. American Heart Fournal, 79, 587-602.

Spann, J. F., Jr., Buccino, R. A., Sonnenblick, E. H., and Braunwald, E. (1967). Contractile state of cardiac muscle obtained from cats with experimentally produced ventricu- 
lar hypertrophy and heart failure. Circulation Research, 21, 341-354.

Spann, J. F., Jr., Covell, J. W., Eckberg, D. L., Sonnenblick, E. H., Ross, J., Jr., and Braunwald, E. (1972). Contractile performance of the hypertrophied and chronically failing cat ventricle. American fournal of Physiology, 223, 11501157.

Spann, J. F., Jr., Mason, D. T., and Zelis, R. F. (1969). The altered performance of the hypertrophied and failing heart. American fournal of the Medical Sciences, 258, 291303.

Toshima, H., Koga, Y., Yoshioka, H., Akiyoshi, T., and Kimura, N. (1975). Echocardiographic classification of hypertensive heart disease. A correlative study with clinical features. Fapanese Heart fournal, 16, 377-393.

Williams, J. F., Jr., and Potter, R. D. (1974). Normal contractile state of hypertrophied myocardium after pulmonary artery constriction in the cat. Fournal of Clinical Investigation, 54, 1266-1272.

Requests for reprints to Dr. Joel S. Karliner, University of California Medical Center, 225 West Dickinson Street, San Diego, California 92103, U.S.A. 